\title{
James G. Holland: A Análise do Comportamento como Prática Política
}

\author{
Alexandre Dittrich* \\ Universidade Federal do Paraná, Curitiba, PR, Brasil
}

\begin{abstract}
RESUMO - James G. Holland foi uma voz dissonante, não apenas na análise do comportamento, mas no contexto mais amplo do pensamento político estadunidense. Este artigo tem como objetivo apresentar as principais críticas e sugestões, direcionadas por Holland, à aplicação da análise do comportamento e avaliar sua relevância no cenário atual. Conclui-se que tais críticas e sugestões são úteis para todos os analistas do comportamento, pois contribuem para que mantenhamos uma cultura de avaliação interna sobre as consequências sociais de nossas práticas e para que analisemos de modo amplo o entrelaçamento de contingências presentes em situações de intervenção e sua influência sobre a formulação de nossos objetivos.
\end{abstract}

PALAVRAS-CHAVE: James G. Holland, behaviorismo radical, análise do comportamento, política

\section{James G. Holland: Behavior Analysis as Political Practice}

\begin{abstract}
James G. Holland was a dissonant voice not only within behavior analysis, but also in the wider context of political thought in the United States. This article aims to present the main criticisms and suggestions made by Holland towards the application of behavior analysis and to evaluate its contemporary relevance. We conclude that such criticisms and suggestions are useful for all behavior analysts, as they contribute to promote the continued internal evaluation of the social consequences of our practices and the extensive analysis of the interlocking contingencies occurring in intervention settings and its influence over our goal-setting.
\end{abstract}

KEYWORDS: James G. Holland, radical behaviorism, behavior analysis, politics

Os analistas do comportamento têm discutido questões éticas desde os primeiros momentos em que a análise do comportamento começou a demonstrar seu potencial para explicar e intervir sobre problemas socialmente relevantes. As publicações pioneiras sobre o tema abordaram problemas éticos variados relativos à aplicação da análise do comportamento (Kanfer, 1965; Krasner, 1962; London, 1970; Ulrich, 1967) e a avaliação desses problemas em diferentes contextos tornou-se uma atividade frequente na comunidade de analistas do comportamento (e. g., Bailey \& Burch, 2011; Behavior Analyst Certification Board, 2016; Berthold, 2001; Fawcett, 1991; Stolz \& Associates, 1978; Vandenberghe, 2005; Winett \& Winkler, 1972; Winkler, 1977; Wolf, 1978).
Além disso, o comportamento ético tem sido objeto de estudo dos analistas do comportamento em contextos experimentais (e. g., Borba \& Tourinho, 2014; De-Farias, 2005; Rachlin, 2002; Weiner, 1977; Zin, Escobal, Esteves, \& Goyos, 2015). Skinner (1971) apresentou, em Beyond Freedom and Dignity, uma influente análise das variáveis que controlam o comportamento ético, que tem servido como fundamento para diversos trabalhos que abordam seu surgimento, manutenção e relevância (e. g., Gewirtz \& Peláez, 1991; Hayes, Gifford, \& Hayes, 1998; Hocutt, 2013; Leigland, 2005; Peláez, 2001; Schlinger, 1995), além de seus desdobramentos filosóficos e políticos (Abib, 2001, 2008; Castro \& De Rose, 2008; Chiesa, 2003; Laurenti \& Lopes, 2015; Melo, Castro, \& De Rose, 2015; Morrow,

*E-mail: aledittrich $@$ ufpr.br

- Submetido: 28/04/2016; Revisado: 30/06/2016; Aceito: 03/10/2016. 
1988; Rakos, 1988a, 1988b, 1989; Ruiz, 2013; Soreth, 2011; Staddon, 2013; Ulman, 1988, 1989, 1991; Vargas, 1982; Vogeltanz \& Plaud, 1992; Zilio \& Carrara, 2009; Zuriff, 1987).

Nessa última categoria, os trabalhos de James G. Holland figuram entre os mais significativos e polêmicos. As análises e proposições realizadas por Holland (1974, 1975, 1978a, 1978b) em relação à aplicação da análise do comportamento destacaram vários aspectos importantes e nem sempre evidentes de tal prática. Holland foi uma voz dissonante não apenas na análise do comportamento, mas no contexto mais amplo do pensamento político estadunidense - pouco afeito a propostas de cunho coletivista.
Este artigo tem como objetivo apresentar as principais críticas e sugestões direcionadas por Holland à aplicação da análise do comportamento e avaliar sua relevância no cenário atual. O conjunto de textos que tomaremos como fundamento para a apresentação das propostas de Holland (1974, 1975, 1978a, 1978b) constituiu uma avaliação impactante das consequências éticas e políticas da aplicação da análise do comportamento. Embora os alvos da crítica sejam especialmente as práticas dos analistas do comportamento estadunidenses até a década de 70, os problemas levantados por Holland permanecem tão relevantes hoje como à época. É possível, contudo, discutir vários aspectos da forma como tais problemas são tratados por Holland, conforme argumentaremos adiante.

\section{SÍNTESE DAS CRÍTICAS E SUGESTÕES DE HOLLAND}

Nesta seção, apresentaremos uma síntese das principais críticas e sugestões de Holland em relação à aplicação da análise do comportamento, tomando como base seu texto seminal sobre o assunto (Are Behavior Principles for Revolutionaries?, publicado em 1974 - doravante, ABPFR), mas, eventualmente, fazendo recurso a outros textos do autor (Holland, 1975, 1978a, 1978b) que complementam e esclarecem suas análises.

Holland abre ABPFR (1974) apontando que a aplicação dos princípios da análise do comportamento tem sido bem sucedida em vários contextos, mas que, apesar disso, há crescentes objeções a tal aplicação. Tais objeções seriam realizadas pelas "pessoas que, nos termos de Beyond Freedom and Dignity de Skinner, são as escritoras da literatura da liberdade e da literatura da dignidade" (pp. 195196). Embora Holland aponte problemas na argumentação de tais pessoas (defendem o livre arbítrio, negam que o comportamento possa ser tratado cientificamente, etc.), ainda assim acredita que "por trás de suas preocupações, há problemas que merecem todo o alarme que elas expressam" (p. 196). Em seguida e durante todo o restante do texto, o autor opõe o sistema presente de contingências comportamentais sociais (tendo como referência básica a sociedade estadunidense) à possibilidade de uma sociedade revolucionária, orientada por outros valores e sustentada por outras contingências.

Quais seriam as contingências do sistema presente? Sociedades capitalistas são hierarquizadas e estratificadas, "com o reforçamento do vencedor se dando às expensas da punição do perdedor...com os estratos mais altos tendo riqueza e privilégios obtidos por meio de seu poder de controlar os estratos mais baixos" (Holland, 1975, p. 81). As contingências de reforçamento na sociedade estadunidense seriam dispostas por uma pequena elite, que "tem sua base nas corporações americanas" (Holland, 1974, p. 197). Essa elite estabeleceria os objetivos do controle comportamental exercido sobre as classes mais baixas: "Um estrato de elite distribui reforçadores para um estrato mais baixo e os objetivos são estabelecidos de cima, seja para adaptar o participante para os objetivos de outros ou para explorá-lo para o ganho de outros" (Holland, 1975, p. 90).

Citando como apoio obras do sociólogo William Domhoff, Holland afirma que essa elite exerce domínio não apenas econômico, mas político, educacional e midiático. ${ }^{1}$ Trata-se de uma "classe dominante largamente hereditária, que estabelece os objetivos gerais para todas as instituições sociais" (1974, p. 198). Abaixo dessa elite, há uma "hierarquia de profissões e papéis para as pessoas" (p. 197). Esse sistema hierárquico se repete também, por exemplo, nas corporações, escolas e quartéis. De acordo com Holland, "os sistemas de reforçamento nessa sociedade são baseados primariamente na aquisição de ganhos materiais pessoais e de privilégios e status pessoais" (p. 197). Tais sistemas, além disso, encorajam o egoísmo e a competição, embora a possibilidade de mobilidade social ascendente na hierarquia seja frequentemente "uma ilusão" (p. 197).

Dentro de tal sistema, de acordo com Holland (1974), há uma grande probabilidade de que o trabalho do psicólogo acabe por apoiar a manutenção do sistema hierárquico, beneficiando as elites que estão em seu topo:

Parece claro que, em nosso atual sistema social, as pessoas que determinarão quem terá seu comportamento modificado e em direção a quais objetivos serão aquelas em posições estabelecidas de poder. A ciência estará a serviço daqueles que comandam os meios para utilizá-la. (p. 198)

Em seguida, Holland (1974) oferece diversos exemplos que ilustrariam tal situação. Boa parte dos exemplos, mencionados em ABPFR, provém do meio militar: técnicas

1 Holland menciona os livros Who Rules America? (1967) e The Higher Circles (1970). O primeiro, considerado um best-seller na década de 60 , recebeu uma edição atualizada em 2009, cobrindo, inclusive, o governo Obama. 
comportamentais são empregadas para várias finalidades, incluindo aperfeiçoar rotinas militares básicas (pp. 198199), "aumentar a tendência do soldado de atirar mais frequentemente e efetivamente" (p. 199) e "pacificar" comunidades invadidas (p. 200). O ponto continuamente destacado por Holland é "o fato de que tais técnicas servem àqueles no poder, não àqueles que recebem diretamente seu impacto" (pp. 199-200) ou, em outras palavras, as técnicas são planejadas e controladas pela cúpula militar para benefício da própria instituição militar, não dos soldados ou dos habitantes das comunidades ocupadas. Holland também menciona o uso da economia de fichas em hospitais psiquiátricos, expressando dúvidas sobre o procedimento:

...as decisões sobre quais comportamentos devem ser reforçados muito frequentemente parecem se apoiar na criação de um tipo de comportamento de enfermaria agradável para o pessoal hospitalar...Admitirei aqui um pouco de minha própria ambiguidade e incerteza. Camas bem-feitas, pacientes bem arrumados, pacientes varrendo o chão e se mantendo asseados podem ser comportamentos valiosos para os próprios pacientes, mas é claro que eles definitivamente refletem o que a Grande Enfermeira quer. (p. 201)

Outro exemplo mencionado por Holland (1974) é o uso de procedimentos de reforçamento em jardins de infância, para "ensinar as crianças a ficar em fila, sentar quietas e evitar se engajar em falar, ou outro comportamento que o professor possa considerar disruptivo. Em outras palavras, [o treinamento] consiste em o estudante fazer o que o estabelecimento escolar demanda" (pp. 201-202). Holland (1975) menciona a revisão de Winett e Winkler (1972) como uma demonstração mais ampla de que, em ambientes escolares, analistas do comportamento têm, via de regra, programado contingências para que os alunos sejam passivos, isto é, não falem e não se movimentem. Programas de reforçamento em prisões e reformatórios apresentam, igualmente, a passividade e a obediência dos internos como objetivo, além de fazer recurso à privação para aumentar a efetividade dos reforçadores (Holland, 1975). Não deveria surpreender, em tais circunstâncias, a emergência de formas variadas de contracontrole, o que de fato ocorre, de acordo com Holland.

O caso da Emery Air Freight ${ }^{2}$ é mencionado por Holland (1975) como um exemplo do uso de técnicas de reforçamento na indústria: “... [os trabalhadores] recebem reforçamentos na forma de sorrisos e aprovação de superiores por empacotar caixas apropriadamente para o transporte. Sorrisos não compram nada para os trabalhadores, mas a eficiência crescente gera milhões em lucros adicionais." (p. 84).

Em todos esses casos, não há uma relação profissionalcliente entre o analista do comportamento e aqueles cujo comportamento é afetado: "Sujeitos desses sistemas de

2 Companhia de cargas estadunidense que operou de 1946 até 2001. controle não são clientes. Eles não podem escolher entre lidar ou não lidar com o profissional. O modificador de comportamento responde a uma terceira pessoa ou organização.” (Holland, 1975, p. 90). Novamente, é essa pessoa ou organização que estabelece os objetivos do trabalho do analista do comportamento e também é ela que se beneficia deles, não as pessoas diretamente afetadas. $\mathrm{O}$ analista do comportamento, portanto, "apoia estruturas de poder estabelecidas" (p. 90). Diante desse quadro, o que o cientista comportamental "envolvido na luta pela justiça" pode fazer? De acordo com Holland (1974),

No mínimo devemos dar prioridade a desenvolvimentos que tenham a possibilidade de ser úteis para as pessoas em geral... Podemos buscar comunicar nossos achados tecnológicos para o povo e desenvolver aplicações que mais provavelmente serão úteis para ele ao invés da elite. É especialmente importante, em relação a isso, que o cientista comportamental analise a operação do controle comportamental em nossa sociedade e comunique essa análise a outros, de modo que eles possam se equipar melhor para o contracontrole. (p. 202)

A promoção do contracontrole é especialmente cara a Holland (1978a), embora ele aponte que sua emergência seja praticamente inevitável em sociedades estratificadas:

Quando o interesse do controlador e do controlado são diferentes, os controladores devem achar extremamente difícil planejar qualquer sistema de administração de contingências tão bem que o controlado não encontre caminhos alternativos para o reforçamento que subvertem o objetivo do controlador. (p. 171)

Mais do que isso, "sistemas de exploração que usem apenas reforçamento positivo são extremamente difíceis de planejar", pois mesmo quando o sistema "parece inteiramente positivo, usualmente coerção e restrição são requeridos em seus limites para manter o controlado dentro das regras do sistema": prisioneiros precisam permanecer em prisões, soldados nos quartéis, alunos nas escolas; "o trabalhador pobre trabalhará por ganhos limitados apenas se for mantido pobre" (Holland, 1978a, p. 171). Analistas do comportamento deveriam "ajudar aquelas vítimas do controle comportamental que estão presentemente engajadas no contracontrole" (Holland, 1975, p. 92). Ainda tratando de contracontrole, Holland (1974) cita, de maneira elogiosa, livros de anarquistas que ensinam técnicas de sabotagem, "grampos" e uso de telecomunicações (p. 204).

Outro caminho apontado por Holland (1975) seria "desenvolver ferramentas comportamentais para indivíduos" (p. 91), isto é, promover diferentes habilidades pessoais, como leitura, escrita e técnicas de autocontrole, que proporcionariam crescente independência para as pessoas afetadas. Por fim, analistas do comportamento poderiam "desenvolver sistemas que reforçariam gestores por ganhos alcançados por aqueles que eles gerenciam" (Holland, 1975, p. 91): professores seriam reforçados pela performance 
de seus alunos, policiais pela redução de crimes, sistemas prisionais pela reabilitação dos prisioneiros, etc. $\mathrm{O}$ fato de que também nesses casos haveria controle hierárquico não escapa a Holland, mas, de acordo com ele, isso "pelo menos daria alguma ajuda para as pessoas menos empoderadas" (p. 92).

Nada disso constituiria uma solução final, porém. Alterações culturais mais profundas seriam necessárias. As recomendações de Holland (1975) alcançam seu ponto culminante quando ele afirma que "instituições refletem a natureza da sociedade" (p. 93) e que, portanto, alterações institucionais pontuais seriam apenas soluções paliativas. Seria preciso mudar a sociedade como um todo, através de novos sistemas de reforçamento que favorecessem práticas participativas de ajuda mútua, coletivistas e anti-individualistas:

O que é preciso é um sistema de mudança do comportamento controlado pelas pessoas que terão seu comportamento mudado. Todos os membros em um sistema de mudança comportamental devem ter um papel integral em determinar os objetivos e em operar o sistema. (1975, p. 92)

Tal sociedade exigiria a "reconstrução do homem", um "sistema de valores revolucionário" produzido por meio de novas contingências de reforçamento (Holland, 1974, p. 206). Essas contingências valorizariam a cooperação ao invés da competição, contribuições para o grupo ao invés de ganhos individuais, altruísmo ao invés de acumulação de riqueza e poder. Holland menciona China (1975) e Cuba (1978b) como exemplos nesse sentido. A experiência do autor como voluntário na construção de moradias em Cuba é descrita em detalhes (1978b) e pontuada por citações de Che Guevara.

Ao sugerir tais mudanças culturais, Holland (1978a) tem especial cuidado em não colocar o analista do comportamento em uma posição de superioridade em relação aos demais membros da sociedade. Embora o analista do comportamento possua "certo conhecimento especializado e habilidades no uso de dados", deve trabalhar como colaborador, parceiro e colega dos integrantes das comunidades (pp. 172-173).

Holland (1974) admite que não pode oferecer uma "resposta definitiva" sobre as mudanças requeridas nas práticas analítico-comportamentais a fim de produzir tal transformação de valores, mas aponta o livro Beyond Freedom and Dignity, de Skinner (1971), como um "guia útil no movimento em direção a uma sociedade revolucionária" (p. 206) e destaca algumas práticas que poderiam "ajustarse a uma nova sociedade", como o sistema de créditos de trabalho sugerido por Skinner (1948) em Walden Two, o sistema de instrução proposto por Keller (no qual “o elitismo de salas de aula convencionais é reduzido"), uma "comunidade reforçadora" autogerida de alcoolistas em recuperação (pp. 206-207) e alternativas de gestão da rotina de hospitais psiquiátricos com a participação dos pacientes (1975, pp. 93-94).

Holland (1974) encerra ABPFR sugerindo que "devemos explorar formas de modificação do comportamento compatíveis com um sistema de valores igualitário, não-materialista e não-elitista, que possa pelo menos ser construtivo para desenvolver os meios para a necessária mudança revolucionária no homem" (p. 208).

\section{BEHAVIORISMO E OUTROS “ISMOS” NA FILOSOFIA POLÍTICA}

De todos os "ismos" que povoam o vocabulário acadêmico, talvez os mais complexos pertençam à filosofia política. Cada "ismo" da filosofia política pode ser explorado em suas diversas nuances e sob diversos pontos de vista, dando origem, com frequência, a "sub-ismos"-adjetivos que qualificam adjetivos, tendências políticas que se mesclam, tornando progressivamente mais difícil e especializada a tarefa de identificar e classificar posicionamentos éticos e políticos de diferentes pessoas e grupos.

Dito isso, os escritos de Holland aparentemente permitem classificá-lo como um socialista marxista - o que muitos chamariam de tendências "de esquerda". Holland se dirige a todos os analistas do comportamento, mas, presumivelmente, nem todos partilham de suas posições políticas. Esse certamente é o caso nos Estados Unidos, mas também no Brasil e nos demais países em que a análise do comportamento se faz presente. De fato, debates entre tendências políticas opostas já ocorrem de longa data entre analistas do comportamento (Morrow, 1988; Rakos, 1988a, 1988b, 1989; Ulman, 1988, 1989).
Cabe, diante disso, perguntar: a filosofia behaviorista radical levaria naturalmente, através de uma rigorosa cadeia de argumentação lógica, à conclusão de que os behavioristas radicais devem, necessariamente, por coerência intelectual, adotar determinada posição político-econômica? Mesmo reconhecendo que quase tudo é possível no campo da argumentação, presumivelmente a resposta é negativa. A filosofia behaviorista radical é um conjunto de regras, pressupostos e proposições em constante evolução, sobre os quais, além disso, nem sempre há acordo. Essa falta de acordo estende-se para o campo do planejamento cultural: há espaço dentro do behaviorismo radical para a defesa das mais variadas posições político-econômicas. ${ }^{3}$ Há behavioristas radicais socialistas, assim como há liberais, assim como há anarquistas, assim como há conservadores, assim como certamente há, em número possivelmente expressivo,

3 Como exemplificado pelos trabalhos há pouco mencionados (Morrow, 1988; Rakos, 1988a, 1988b, 1989; Ulman, 1988, 1989), além dos próprios escritos de Holland (1974, 1975, 1978a, 1978b). 
behavioristas radicais que pouco ou nada se interessam por política e economia.

É razoável sugerir, portanto, que a comunidade behaviorista radical dificilmente se unirá consensualmente em torno de qualquer projeto político-econômico de larga escala, o que não impede que grupos específicos de behavioristas radicais o façam. Como sempre ocorre nas democracias, resta-nos a discussão, a argumentação e a ação em torno de projetos políticos que, por quaisquer motivos, consideremos relevantes, mas sem a pretensão de que estejamos, com isso, representando politicamente a totalidade da comunidade behaviorista radical ou expressando com especial fidelidade os princípios dessa filosofia.

O fato de sermos analistas do comportamento pode, eventualmente, fazer com que alguns de nós atribuam, a si mesmos ou à nossa comunidade, alguma autoridade especial para realizar prescrições éticas e políticas: apenas analisamos as contingências e disso extraímos o melhor planejamento. Teríamos tal autoridade? O que explica o fato de que diferentes analistas do comportamento extraem, da análise das mesmas contingências sociais, prescrições tão diferentes?

Grupos políticos variados podem sustentar a pretensão de que possuem verdades científicas sobre o que é melhor para a humanidade. Esses grupos podem se negar ao diálogo com quem não reconhece tal verdade, ou mesmo tentar impô-la aos demais. Seria algum partido ou corrente política proprietário da última palavra sobre o que a humanidade precisa, ou sobre os destinos da história? Nem mesmo filósofos e cientistas políticos - profissionais cujo objeto de estudo são relações comportamentais políticas - alcançam acordos sobre o que é melhor para as culturas - pelo contrário, em tais campos, as divergências são evidenciadas e aprofundadas pelo desenvolvimento dos diversos "ismos".

O debate político-econômico fundamentado na presunção de autoridade epistemológica ou moral empobrece os termos da argumentação e, com frequência, sustenta discursos maniqueístas, que separam os "bons" dos "maus"- quem faz a distinção, é claro, sempre está entre os bons. Ora, supostamente todos as correntes político-econômicas querem "o bem", mas o concebem de diferentes formas e/ou buscam produzi-lo com diferentes métodos. Isso não indica diferenças no caráter moral dos contendores, mas na história de seleção que produziu seu repertório comportamental (Dittrich, 2008).

Disso não precisa e não deve resultar, porém, a paralisia política. Como aponta Lopes (2015), a política é "o campo no qual que se enfrenta o desafio de lidar com a diferença" (p. 28). A democracia, enquanto conjunto de práticas políticas, é uma tentativa de administrar as diferenças entre as histórias seletivas dos membros das culturas. $\mathrm{Na}$ democracia, podemos e devemos defender nossos objetivos e métodos, mesmo sabendo que podemos errar e mudar nossas posições. A grande lição política de um livro como Walden Two (Skinner, 1948), mais do que a proposição de um modelo específico de sociedade, é a disposição constante para a experimentação. Devemos estar prontos a avaliar novos dados e argumentos e a mudar nosso comportamento de acordo com eles.

Behavioristas radicais que discordam das posições políticas de Holland podem encontrar, em suas análises e propostas, oportunidades relevantes para avaliar suas próprias posições. Seriam as análises de Holland pertinentes? Deveríamos seguir suas sugestões? Se não, por quê? Quais as alternativas?

\section{ESTRATIFICAÇÃO, HIERARQUIZAÇÃO E OS OBJETIVOS DA ANÁLISE DO COMPORTAMENTO}

Conforme aponta Holland (1974), vivemos em sociedades estratificadas e hierarquizadas, com notórias desigualdades sociais. Tais desigualdades se verificam de diversos modos nas relações sociais - em especial, como aponta Holland, na distribuição desigual de poder e de renda. As práticas verbais que chamamos genericamente de "mentalistas" - a atribuição de causas inerentes ao indivíduo para explicar seu comportamento - podem servir, como aponta Holland (1978), para a manutenção de tal estratificação: "O uso padronizado da culpabilização da vítima e das causas internas por si só tem uma base comportamental, dado que ela reforça o status quo" (p. 173), isto é, se os ricos e poderosos merecem o que têm por suas qualidades pessoais, os pobres e não-poderosos são também responsáveis por seu infortúnio.

A inadequação de tais formas de explicação foi insistentemente apontada por Skinner (e. g., 1953/1965,
1971, 1974). Holland (1975) toma tal inadequação como fundamento para sugerir que a análise do comportamento redirecione os objetivos de sua aplicação: não se trata de produzir mudanças no comportamento de indivíduos "com problemas" e nem mesmo de tão somente produzir mudanças no funcionamento de instituições. Se de fato "instituições refletem a natureza da sociedade" (p. 93), Holland se mostra coerente ao propor mudanças na própria organização social, política e econômica das sociedades e também ao participar diretamente da tentativa de realização de tais mudanças, como fez em sua viagem a Cuba (1978b).

Contudo, as análises de Holland sobre os objetivos da atuação dos analistas do comportamento podem ser relevantes mesmo para aqueles que discordam de suas posições políticas mais amplas. Antes mesmo do planejamento de qualquer intervenção comportamental, é necessária uma avaliação sobre a origem da demanda: quem 
a faz, quem a financia e com que objetivos? Concordamos com tais objetivos? Quem será beneficiado pela intervenção e de que forma? A relevância de tais perguntas independe de posições políticas e respondê-las pode ser mais complexo do que parece à primeira vista, como bem ilustra Botomé (1981/1997) ao avaliar as demandas apresentadas por funcionários públicos de uma agência de saúde.

Além disso, é importante que os próprios analistas do comportamento estejam continuamente dispostos a discutir entre si a pertinência de seus objetivos e resultados em diferentes contextos. Holland é um representante emblemático dessa disposição crítica, mas há vários outros (e. g., Grant, 2014; Nordyke, Baer, Etzel, \& Leblanc, 1977; Winett \& Winkler, 1972). Grant (2014), por exemplo, aponta a importância de reduzir a efetividade de reforçadores generalizados como dinheiro e bens materiais e aumentar a efetividade de reforçadores generalizados alternativos (relativos a arte, conhecimento, esportes, relações humanas, etc.), até mesmo considerando a necessidade de que o consumo de reforçadores seja compatível com a sustentabilidade ambiental.

Para os analistas do comportamento que concordam com as críticas de Holland, elas podem, eventualmente, soar intimidantes ou mesmo paralisantes. Analistas do comportamento normalmente trabalham junto a instituições, mas se "instituições refletem a natureza da sociedade" (Holland, 1975, p. 93), apresentando ordenamentos hierárquicos bem definidos, as chances de atuar de acordo com as recomendações de Holland podem ser restritas. Avaliar quando estamos agindo em favor dos controladores ou dos controlados nem sempre é tarefa simples, como o próprio Holland eventualmente reconhece (1974, p. 201).

Além disso, como mencionamos anteriormente, Holland acaba por concluir que alterações institucionais pontuais são apenas soluções paliativas: se as instituições "refletem a natureza da sociedade", a sociedade como um todo deve mudar - do contrário, mudanças comportamentais ocorridas em ambientes institucionais perderão efeito quando as pessoas afetadas retornarem aos ambientes que originalmente produziram os problemas (Holland, 1978a). A despeito disso, o próprio Holland não se furta, como vimos, a chancelar certos tipos de ações em ambientes institucionais, isto é, aquelas que favorecem relações mais igualitárias, não hierárquicas.
Embora o analista do comportamento deva manter uma autocrítica constante, buscando identificar as variáveis que controlam o processo de formulação dos objetivos de sua intervenção, ele não pode ter a pretensão de ter certeza de que está agindo da forma mais justa. A ética e a política, conforme sugerimos anteriormente, não permitem conclusões epistemologicamente ou moralmente absolutas. A eventual hesitação que pode derivar da incerteza sobre a adequação dos objetivos da intervenção é salutar, desde que não resulte em inércia. Ao tomar decisões e agir assumimos riscos, mas espera-se do analista do comportamento que exerça a autocrítica - científica, técnica e ética - não apenas ao planejar suas intervenções, mas também ao implementálas e ao avaliar seus resultados. Igualmente, espera-se que o analista do comportamento esteja pronto a avaliar eventuais críticas externas à sua atuação, especialmente as que provém das pessoas e grupos junto aos quais trabalha (Fawcett, 1991; Winett, 1991; Wolf, 1978). A responsabilidade de decidir e agir deve ser acompanhada por uma flexibilidade que nos permita reconhecer e corrigir eventuais problemas em nossas intervenções. Cabe aqui a importante observação de Botomé (1981/1997):

É importante reconhecer que são os que fazem um trabalho, ao arriscarem as consequências de decisões e de gestos, quem cria condições para que alguém ... possa examinar o que ocorre quando o trabalho é feito. As críticas existentes ... só são possíveis porque houve gestos, decisões, ações... O mérito maior, sem dúvida, cabe a quem fez os gestos e não ao crítico que os examina. (p. 1)

A existência de hierarquias nas instituições sociais pode ou não ser vista como um problema, mas, mesmo os exemplos de intervenção apontados por Holland (1978) como positivos apresentam, como reconhece o autor, "a contradição de um Frazier - um planejador da elite" (p. 172). O mesmo se aplica, agora como na década de 70 , às sociedades cubana e chinesa, elogiadas por Holland (1974) (Fidel Castro e Mao Tsé-Tung são mencionados pelo autor como líderes de revoluções bem-sucedidas). Assim, a mera existência de hierarquias nas instituições não deve impedir o trabalho do analista do comportamento junto a elas, a despeito da importância de avaliar quem participa do planejamento de contingências e a quem ele beneficia.

\section{A ATUALIDADE DAS CRÍTICAS E SUGESTÕES DE HOLLAND}

É possível perguntar se as críticas e sugestões de Holland permanecem relevantes, considerando que os textos do autor, ora sob análise, foram publicados há quatro décadas. A aplicação da análise do comportamento sofreu transformações importantes nesse período.

Desde seu início formal, a análise do comportamento aplicada mostrou preocupação em lidar com comportamentos socialmente importantes, ao ponto de Baer, Wolf e Risley (1968) afirmarem que "na aplicação comportamental, o comportamento, estímulo e/ou organismo sob estudo é escolhido por causa de sua importância para o homem e a sociedade" e que o próprio adjetivo "aplicada" "não é determinado pelos procedimentos de pesquisa, mas pelo interesse que a sociedade demonstra nos problemas sob estudo" (p. 92). Essa postura exige que os analistas do comportamento avaliem e sejam responsivos às demandas sociais. Obviamente, os analistas do comportamento não têm condições de definir, isoladamente, quais comportamentos 
são "socialmente importantes". Como também afirmam Baer et al. (1968), "a avaliação do que é uma 'boa' sociedade é, em si mesma, um comportamento de seus membros" (p. 92).

A análise do comportamento aplicada fez claros avanços no sentido de avaliar o que os membros da sociedade junto aos quais atua consideram socialmente importante, no que tange aos objetivos, métodos e resultados das intervenções. A chamada validação social teve papel proeminente nesse sentido (Geller, 1991; Wolf, 1978), mas é possível identificar outras contribuições (e. g., Botomé, 1981/1997; Fawcett, 1991; Winett, 1991). No contexto estadunidense, esses avanços ocorreram, em parte, em resposta à crescente cobrança da sociedade em relação à adequação ética das aplicações da análise do comportamento, ilustrando a "íntima interdependência entre a ciência, sua prática e seu público" (Rutherford, 2006, p. 205).

A despeito da importância da validação social, a decisão sobre quais problemas serão privilegiados na pesquisa e na prestação de serviços ainda cabe, primariamente, aos próprios analistas do comportamento. $\mathrm{O}$ julgamento desses sobre quais problemas são socialmente relevantes depende das especificidades das demandas apresentadas pelas comunidades e instituições junto às quais atuam, mas também de contingências idiossincráticas presentes na história de vida de cada analista. Assim, diferentes analistas do comportamento podem ter julgamentos variados sobre como melhorar a vida social, isto é, sobre quais objetivos são socialmente importantes em suas pesquisas e intervenções. Discordâncias entre os analistas do comportamento sobre quais deveriam ser seus objetivos não são incomuns, como exemplificado por diferentes posicionamentos sobre práticas educativas (O’Leary, 1972; Winett \& Winkler, 1972) e orientação sexual (Carvalho, Silveira, \& Dittrich, 2011).

Adicionalmente, cabe notar o crescimento das pesquisas e da prestação de serviços direcionados ao autismo e a outros transtornos do desenvolvimento, induzido pelo sucesso na demonstração empírica da efetividade da análise do comportamento nesse campo e pelas consequências desse sucesso sobre as oportunidades de colocação profissional. Embora a atuação dos analistas do comportamento em tal âmbito certamente responda a uma importante demanda social, a atual predominância desse tipo de pesquisa e intervenção obviamente não se explica apenas em função dela, mas também por variáveis relativas a empregabilidade e remuneração.

O apelo de Normand e Kohn (2013) para que os analistas do comportamento "estendam o alcance dos serviços comportamentais para um âmbito mais diversificado de espaços e para populações mais variadas" (p. 109) parece hoje especialmente oportuno. Certamente há potencial para essa extensão, como demonstra a ampla variabilidade de intervenções promovidas por analistas do comportamento, ainda que muitas dessas intervenções tenham baixa frequência ou constituam exemplos isolados (Mayer,
Sulzer-Azaroff, \& Wallace, 2012; Northup, Vollmer, \& Serrett, 1993).

A crescente profissionalização da aplicação da análise do comportamento tem sido acompanhada por avanços importantes nas reflexões sobre suas implicações éticas. A publicação recente do Professional and Ethical Compliance Code for Behavior Analysts (BACB, 2016) é especialmente emblemática nesse sentido. Embora não seja parte de nossos objetivos, uma análise desse código à luz das críticas e sugestões de Holland seria oportuna. Por ora, cabe notar que o código afirma o seguinte:

A responsabilidade dos analistas do comportamento é com todas as partes afetadas pelos serviços analítico-comportamentais. Quando múltiplas partes estão envolvidas e puderem ser definidas como clientes, uma hierarquia de partes deve ser estabelecida e comunicada desde o início da relação definida. Analistas do comportamento identificam e comunicam quem é o beneficiário primário final dos serviços em qualquer situação dada e advogam por seu melhor interesse. (BACB, 2016, p. 6)

Analistas do comportamento envolvem o cliente no planejamento e no consentimento para programas de mudança de comportamento. (BACB, 2016, p. 12)

Tomando as análises de Holland como referência, regras como essas constituem um avanço importante, mas podem surgir dúvidas sobre como definir a "hierarquia de partes" ou sobre como identificar o "beneficiário primário final" de cada intervenção. A solução exigiria uma análise das características particulares de cada caso, mas não seria estranho se analistas do comportamento tivessem opiniões discordantes. As perguntas de Holland continuam aqui tão relevantes como há quatro décadas: quem demanda o serviço, quem paga por ele e quem de fato se beneficia dele? A análise do comportamento aplicada tem reconhecido a importância de buscar respostas claras e explícitas a essas questões, o que vai ao encontro de pelo menos parte das sugestões de Holland.

Os analistas do comportamento que subscrevem as críticas de Holland podem, em última análise, considerar que somente mudanças profundas e abrangentes nas contingências sociais, políticas e econômicas que governam nossas sociedades seriam objetivos aceitáveis e coerentes. O próprio Holland qualifica tais mudanças como revolucionárias e sugere que a dissolução de ordenamentos hierárquicos seria uma meta importante nesse contexto. Quer concordem ou não com tais posições, analistas do comportamento trabalham hoje em sociedades nas quais tais ordenamentos hierárquicos existem e precisam lidar com as implicações éticas disso. De fato, as críticas e sugestões de Holland são, ainda hoje, relevantes justamente em função da onipresença de tais ordenamentos, pois eles obrigam os analistas do comportamento a se perguntarem a serviço do que e de quem empregam seu conhecimento científico. 


\section{CONCLUSÃO}

A reflexão sobre os textos de Holland analisados neste trabalho pode ser útil para todos os analistas do comportamento, sejam quais forem suas posições políticas, quer as tenham claramente ou não. Os analistas do comportamento estão acostumados a receber os mais variados tipos de críticas provenientes de fora de sua comunidade, mas é importante que, além de atentar para tais críticas, mantenham deliberadamente uma cultura de avaliação interna sobre as consequências sociais de suas práticas.

As análises de Holland oferecem uma visão panorâmica sobre o entrelaçamento de contingências envolvidas em situações de intervenção que podem, à primeira vista, parecer simples. As perguntas de Holland são instigantes e nem sempre são feitas como parte da rotina dos analistas do comportamento: Quais contingências sociais explicam o comportamento de pessoas que são, via de regra, tratadas como "problemas" por psicólogos? Qual a origem das demandas sociais que se apresentam ao analista do comportamento? O que controla o comportamento dos que querem controlar comportamentos, incluindo os próprios analistas do comportamento?

Ao buscar respostas para tais perguntas, Holland foi naturalmente levado (assim como Skinner) à conclusão de que a análise do comportamento culmina, necessariamente, em uma análise de contingências sociais, políticas e econômicas: "É fácil para um psicólogo tradicional treinado em laboratório ficar embaraçado por abordar, mesmo que de passagem, a ciência política, mas, por fim, o uso potencial das técnicas de modificação do comportamento para o planejamento cultural torna tal abordagem inevitável" (1974, pp. 196-197). Assim como outras pessoas e grupos, buscamos, diante disso, encontrar respostas sobre quais resultados devemos produzir e como podemos fazê-lo. Holland tem suas próprias respostas, mas deveria ser óbvio que elas são as respostas de um analista do comportamento e não da análise do comportamento. Analistas do comportamento podem concordar ou não com as respostas de Holland, mas, nesse caso, como em vários outros, o simples fato de que perguntas relevantes tenham sido feitas pode ser tão importante quanto as eventuais respostas.

\section{REFERÊNCIAS}

Abib, J. A. D. (2001). Teoria moral de Skinner e desenvolvimento humano. Psicologia: Reflexão e Crítica, 14, 107-117.

Abib, J. A. D. (2008). Ensaio sobre desenvolvimento humano na pós-modernidade. Psicologia em Estudo, 13, 417-427.

Baer, D. M., Wolf, M. M., \& Risley, T. R. (1968). Some current dimensions of applied behavior analysis. Journal of Applied Behavior Analysis, 1, 91-97.

Bailey, J., \& Burch, M. (2011). Ethics for behavior analysts. New York, NY: Routledge.

Behavior Analyst Certification Board. (2016). Professional and ethical compliance code for behavior analysts. Littleton, CO: Author. Recuperado de http://bacb.com/wp-content/ uploads/2016/03/160321-compliance-code-english.pdf

Berthold, H. C., Jr. (2001). Ethics and behavior analysis in management. In C. Merle Johnson, W. K. Redmon, \& T. C. Mawhinney (Eds.), Handbook of organizational performance: Behavior analysis and management (pp. 415-436). New York: Haworth Press.

Borba, A., \& Tourinho, E. Z. (2014). Establishing the macrobehavior of ethical self-control in an arrangement of macrocontingencies in two microcultures. Behavior and Social Issues, 23, 68-86.

Botomé, S. P. (1997). Serviço à população ou submissão ao poder: O exercício do controle na intervenção social do psicólogo. Recuperado de https://obmbrasil.files.wordpress.com/2013/12/ botome-servico-a-populacao.pdf(Original publicado em 1981)

Carvalho, M. R. A., Silveira, J. M., \& Dittrich, A. (2011). Tratamento dado ao tema "homossexualidade" em artigos do Journal of Applied Behavior Analysis: Uma revisão crítica. Revista Brasileira de Análise do Comportamento, 7, 72-81.

Castro, M. S. L. B., \& De Rose, J. C. (2008). A ética skinneriana e a tensão entre descrição e prescrição no behaviorismo radical. Santo André, SP: ESETec.

Chiesa, M. (2003). Sobre la meta-ética, la ética normativa y el conductismo. Revista Latinoamericana de Psicología, 35, 289-297.
De-Farias, A. K. C. R. (2005). Comportamento social: Cooperação, competição e trabalho individual. In J. Abreu-Rodrigues \& M. R. Ribeiro (Eds.), Análise do comportamento: Pesquisa, teoria e aplicação (pp. 265-281). Porto Alegre: Artmed.

Dittrich, A. (2008). O problema da "justificação racional de valores" na filosofia moral skinneriana. Revista Psicolog, 1, 21-26.

Fawcett, S. B. (1991). Some values guiding community research and action. Journal of Applied Behavior Analysis, 24, 621-636.

Geller, E. S. (Ed.). (1991). Social validity: Multiple perspectives [Seção Especial]. Journal of Applied Behavior Analysis, 24, 189-249.

Gewirtz, J. L., \& Peláez, M. (1991). Proximal mechanisms in the acquisition of moral behavior patterns. In W. M. Kurtines \& J. L. Gewritz (Eds.), Moral behavior and development: Advances in theory, research and application (Vol. 1, pp. 153-182) Hillsdale, NJ: Enrlbaum.

Grant, L. K. (2014). Insatiability: Part of the problem or part of the solution? Behavior and Social Issues, 23, 52-67.

Hayes, S., Gifford, E., \& Hayes, G. (1998). Moral behavior and the development of verbal regulation. The Behavior Analyst, 21, 253-279.

Hocutt, M. (2013). A behavioral analysis of morality and value. Behavior and Philosophy, 36, 239-249.

Holland, J. G. (1974). Are behavioral principles for revolutionaries? In F. S. Keller \& E. Ribes-Iñesta (Eds.), Behavior modification: Applications to education (pp. 195-208). New York: Academic Press.

Holland, J. G. (1975). Behavior modification for prisoners, patients, and other people as a prescription for the planned society. Revista Mexicana de Análisis de la Conducta, 1, 81-95.

Holland, J. G. (1978a). Behaviorism: Part of the problem or part of the solution? Journal of Applied Behavior Analysis, 11, 163-174.

Holland, J. G. (1978b). To Cuba with the Venceremos Brigade. Behaviorists for Social Action, 1, 21-28. 
Kanfer, F. H. (1965). Issues and ethics in behavior manipulation. Psychological Reports, 16, 187-196.

Krasner, L. (1962). Behavior control and social responsibility. American Psychologist, 17, 199-204.

Laurenti, C., \& Lopes, C. E. (2015). Cultura, democracia e ética. Reflexões comportamentalistas. Maringá: Eduem.

Leigland, S. (2005). Variables of which values are a function. The Behavior Analyst, 28, 133-142.

London, P. (1970). Moral issues in behavior modification. In R. H. Bradfield (Ed.), Behavior modification: The human effort. San Rafael, CA: Dimensions.

Lopes, C. E. (2015, Quarter I). The political discourses of behavior analysis. Operants, 27-32.

Mayer, G. R., Sulzer-Azaroff, B., \& Wallace, M. (2012). Achieving lasting behavior change through behavior analysis. In G. R. Mayer, B. Sulzer-Azaroff, \& M. Wallace (Eds.), Behavior analysis for lasting change (2a ed.). Cornwall-on-Hudson, NY: Sloan.

Melo, C. M., Castro, M. S. L. B., \& De Rose, J. C. (2015). Some relations between culture, ethics and technology in B. F. Skinner. Behavior and Social Issues, 24, 39-55.

Morrow, J. E. (1988). Is socialism flawed?. Behavior Analysis and Social Action, 6(2), 23-24.

Nordyke, N., Baer, D. M, Etzel, B., \& Leblanc, J. M. (1977). Implications of stereotyping and modification in sex role. Journal of Applied Behavior Analysis, 10, 553-557.

Normand, M. P., \& Kohn, C. S. (2013). Don't wag the dog: Extending the reach of applied behavior analysis. The Behavior Analyst, 36, 109-122.

Northup, J., Vollmer, T. R., \& Serrett, K. (1993). Publication trends in 25 years of the Journal of Applied Behavior Analysis. Journal of Applied Behavior Analysis, 26, 527-537.

O'Leary, K. D. (1972). Behavior modification in the classroom: A rejoinder to Winett and Winkler. Journal of Applied Behavior Analysis, 5, 505-511.

Peláez, M. (2001). Morality as a system of rule-governed behavior and empathy. Behavioral Development Bulletin, 1, 8-14.

Rachlin, H. (2002). Altruism and selfishness. Behavioral and Brain Sciences, 25, 239-250.

Rakos, R. F. (1988a). Capitalism, socialism, and behavioral theory. Behavior Analysis and Social Action, 6(2), 16-22.

Rakos, R. F. (1988b). Scientific analysis or political ideology? Behavior Analysis and Social Action, 6(2), 32.

Rakos, R. F. (1989). Socialism, behavioral theory, and the egalitarian society. Behavior Analysis and Social Action, 7, 23-29.

Ruiz, M. R. (2013). Values and morality: Science, faith, and feminist pragmatism. The Behavior Analyst, 36, 251-254.

Rutherford, A. (2006). The social control of behavior control: Behavior modification, individual rights, and research ethics in America, 1971-1979. Journal of the History of the Behavioral Sciences, 42, 203-220.

Schlinger, H. D. (1995). A behavior analytic view of child development. New York: Plenum Press.

Skinner, B. F. (1948). Walden Two. New York: Macmillan.
Skinner, B.F. (1965). Science and human behavior. New York: Macmillan. (Original publicado em 1953)

Skinner, B. F. (1971). Beyond freedom and dignity. New York: Alfred A. Knopf.

Skinner, B. F. (1974). About behaviorism. New York: Alfred A. Knopf.

Soreth, M. E. (2011). Against the dichotomy of morality and selfinterest: A review of Power's "A Problem from Hell": America and the Age of Genocide. Behavior and Social Issues, 20, 32-43.

Staddon, J. E. R. (2013). Faith, fact and behaviorism. The Behavior Analyst, 36, 229-238.

Stolz, S. B. and Associates (1978). Ethical issues in behavior modification. San Francisco: Jossey-Bass.

Ulman, J. D. (1988). Just say no to commodity fetishism: A reply to Rakos. Behavior Analysis and Social Action, 6(2), 25-31.

Ulman, J. D. (1989). Beyond the carrot and the stick: A behavioral rejoinder to Rakos. Behavior Analysis and Social Action, 7, 30-34.

Ulman, J. D. (1991). Toward a synthesis of Marx and Skinner. Behavior and Social Issues, 1, 57-70.

Ulrich, R. (1967). Behavior control and public concern. The Psychological Record, 17, 229-234.

Vandenberghe, L. (2005). Uma ética behaviorista radical para a terapia comportamental. Revista Brasileira de Terapia Comportamental e Cognitiva, 7, 55-66.

Vargas, E. A. (1982). Hume's "ought" and "is" statement: A radical behaviorist perspective. Behaviorism, 10, 1-23.

Vogeltanz, N. D., \& Plaud, J. J. (1992). On the goodness of Skinner's system of naturalistic ethics in solving basic value conflicts. The Psychological Record, 42, 457-468.

Weiner, H. (1977). An operant analysis of human altruistic responding. Journal of the Experimental Analysis of Behavior, 27, 515-528.

Winkler, R. C. (1977). What types of sex-role behavior should behavior modifiers promote?. Journal of Applied Behavior Analysis, 10(3), 549-552.

Winett, R. A., \& Winkler, R. C. (1972). Current behavior modification in the classroom: Be still, be quiet, be docile. Journal of Applied Behavior Analysis, 5, 499-504.

Winett, R. A. (1991). Caveats on values guiding community research and action. Journal of Applied Behavior Analysis, 24, 637-639.

Wolf, M. M. (1978). Social validity: The case for subjective measurement or how applied behavior analysis is finding its heart. Journal of Applied Behavior Analysis, 11, 203-214.

Zilio, D., \& Carrara, K. (2009). B. F. Skinner: Teórico da ciência e teórico da moral?. Arquivos Brasileiros de Psicologia, 61, 1-12.

Zin, G., Escobal, G., Esteves, G., \& Goyos, C. (2015). Sharing Game: Influence of gender, cost of response, history of reinforcement, and amount of money in the resource distribution of undergraduate students. Behavior Analysis: Research and Practice, 15, 65-80.

Zuriff, G. (1987). Naturalist ethics. In S. Modgil \& C. Modgil (Eds.), B. F. Skinner: Consensus and controversy (pp. 309-318). Philadelphia, PA: Falmer Press. 